CERA sent its first survey to all residency programs in June 2011. Currently it surveys residency directors 2 times per year; general residency faculty annually, and clerkship directors and medical school faculty annually. This coordinated effort around surveying constituents results in higher quality questions and fewer surveys.

\section{So What?}

Have you ever considered conducting a survey you thought explored important issues in family medicine and could have enduring value for our discipline, but never pursued it because of any of the following barriers?

- My program is too small so my sample would be too small

- I don't know how I would get other residency programs to take part in this

- I have never been trained in survey design and there is no one in my program or institution to help me

- I don't know how to move from a survey question to a research project

The mission and purpose of CERA address all of the barriers above.

\section{Now What?}

As requirements around scholarly activity for faculty put greater emphasis on peer review, CERA can play an important role in faculty development for your program and help increase scholarly productivity. The mentoring and guidance built into the infrastructure of CERA can provide the resources that are simply lacking and unavailable to many programs. Programs should encourage faculty to submit questions to CERA for primary research as well as utilize the data in the CERA clearinghouse for secondary data analysis.

We cannot rely on the designated department researchers to solely carry the responsibility of creating and sustaining family medicine research efforts. Teaching scholarly inquiry and evaluation is an obligation of family medicine residency programs and we must continue to explore opportunities like CERA that can help us fulfill that obligation.

For more information regarding CERA, visit http:// www.stfm.org/initiatives/CERA.cfm.

Lisa Maxwell, MD, Michael Mazzone, MD Stoney Abercrombie, $M D_{i}$ Brian Crownover, $M D_{i}$ Grant Hoekzema, MD, Nathan Krug, $M D_{i}$ Karen Mitchel, MDi Stephen Schultz, MD, Todd Shaffer, MD, MBA, Michael Tuggy, MD

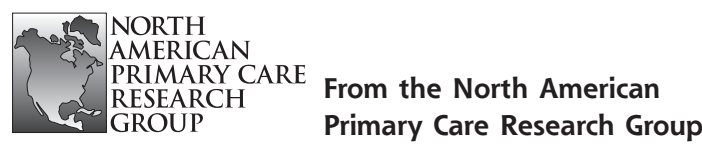

Ann Fam Med 2012;10:577-578. doi:10.1370/afm.1458.

\section{PBRN CONFERENCE A SUCCESS}

On June 21-22, 2012, NAPCRG tried something new. It worked. On these dates NAPCRG held its first annual practice-based research network (PBRN) conference. This meeting was supported by a conference grant from AHRQ, who has a longstanding interest in PBRN work, and who, until now had put on an annual PBRN conference. This meeting therefore represents a new, formal relationship with AHRQ, a new annual meeting for NAPCRG, and a chance to work with a whole new set of scientists, educators, and clinicians who care about practice-based research. Over 200 registrants attended the conference, from 6 countries. Japan! Romania! Brazil! Australia! And 30 investigators from Canada! Under NAPCRG's stewardship, this conference could well become-most likely will become-a world forum for PBRN work. Moreover, a broad range of disciplines were represented, including family medicine, general internal medicine, pediatrics, nursing, public health, dentistry, pharmacy, psychology, and social work.

All of this is good, but the real news has to do with how PBRNs are evolving. For 3 decades, practice-based research networks have been a core resource in the primary care research armamentarium, and a preferred platform for describing practices and clinical conditions, as well as for testing clinical interventions. At this PBRN meeting we heard about:

- Networks of networks linked together with elegant, efficient, lean infrastructures to answer difficult clinical or services questions

- Very large networks of practices linked together by their electronic health records. Some of these networks are large enough to tackle detailed comparative effectiveness trials

- Hybrid PBRN/CBPR networks that incorporate community resources, community boards, and deep community partnerships. These networks can test interventions that make use of public health, community health, and primary care resources

- PBRNs whose datasets are linked to very large administrative datasets, or claims datasets, that can produce complete services data

- PBRNs that cut across disciplines (eg, primary care, public health, dentistry, behavioral health) 
to address health and heath care issues that occur across these multiple sectors

- Multinational PBRNs that take nesting to a whole higher level — that afford comparisons of similar clinical conditions in different systems of care

- PBRNs that are taking on questions of practice redesign and system change, and are proving useful even with the sophisticated designs required of quality improvement efforts, during which interventions are continuously evolving; and

- PBRNs that are used as platforms for disseminating innovations and keeping practitioners close to practice improvement research

Two additional highlights of this meeting merit mention: the 2 plenaries. The first was delivered by Joe Selby, Executive Director of PCORI, who described how well suited PBRNs are to addressing patientcentered outcomes research. The second was a panel discussion presented by Larry Green, Jon Kerner, Jim Mold, and Jack Westfall, who discussed the intersection of public health and primary care, and how PBRNs have begun to address this interface as it applies to cancer prevention, asthma control, and health and health care extension in a statewide network.
During an all-attendees evaluation and suggestion session at the conclusion of the conference, participants strongly endorsed this conference as a standing event, and suggested that we should consider expanding the international participation, deepening the interprofessional conversation, fostering additional opportunities for funders and researchers to engage with one another, continuing to explore the innovative ways researchers are designing PBRNs and PBRN studies, offering special events or sessions for PBRN staff, and above all, expanding the venues at which research results could be showcased.

Practice-based research networks have come of age, and are now capable of answering difficult, complex, and important questions. This conference demonstrated that to good effect. At the end of the conference, NAPCRG's Board of Directors concluded as much and recommended that efforts begin immediately to seek support and plan improvements for next year's PBRN conference.

Frank deGruy, NAPCRG President

\section{Get the Annals of Family Medicine by E-mail}

Make sure you see every new issue

while it's fresh; have the table of

contents sent to you by e-mail for

easy access to articles of interest.

Don't miss important research.

Request the e-mail table of contents at http://lyris.aafp.org/subscribe/annals/.

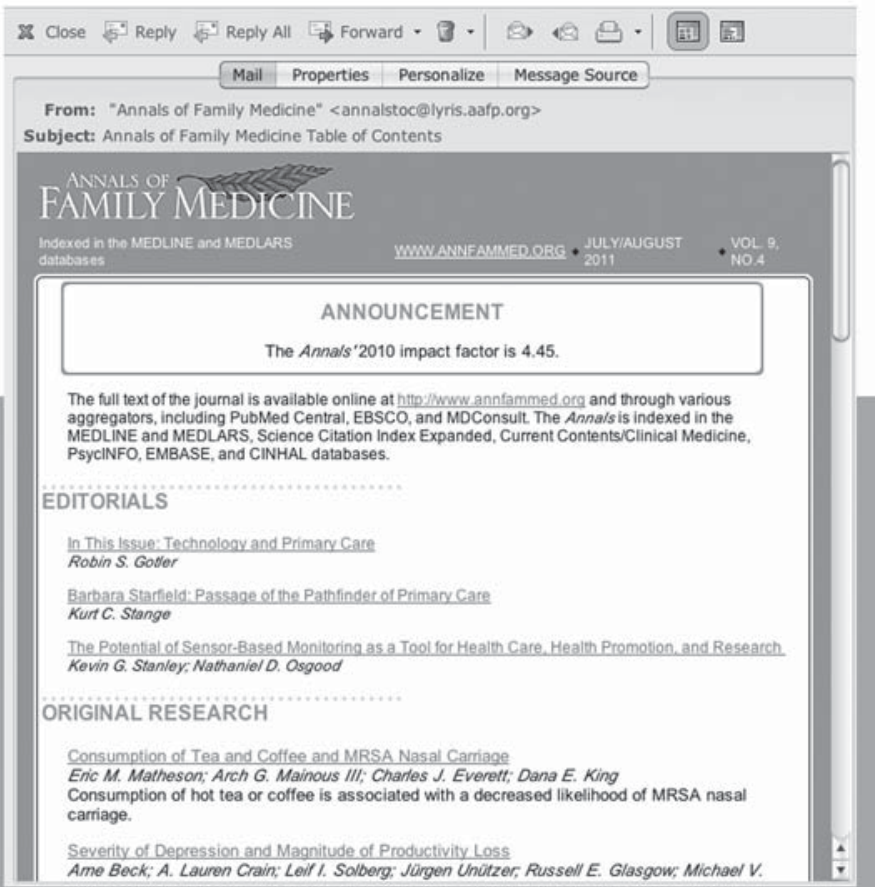

